\title{
Sonographic Measurement of the Umbilical Cord and Its Vessels and Their Relation with Fetal Anthropometric Measurements
}

\author{
Sheida Rostamzadeh, ${ }^{1, *}$ Mojgan Kalantari, ${ }^{1}$ Mona Shahriari, ${ }^{2}$ and Madjid Shakiba ${ }^{2}$ \\ ${ }^{1}$ Department of Radiology, Mahdieh Hospital, Shahid Beheshti University of Medical Sciences, Tehran, Iran \\ ${ }^{2}$ Advanced Diagnostic and Interventional Radiology Research Center (ADIR), Tehran University of Medical Sciences, Tehran, Iran \\ ${ }^{*}$ Corresponding author: Sheida Rostamzadeh, Department of Radiology, Mahdieh Hospital, Shahid Beheshti University of Medical Sciences, Tehran, Iran. Tel: +98-9123909718, Fax: \\ +98-2122439784, E-mail:s_rst2003@yahoo.com
}

Received: June 4, 2013; Revised: October 10, 2013; Accepted: December 15, 2013

\begin{abstract}
Background: It has been established that presence of lean umbilical cord with reduced Wharton's jelly in sonographic scans is a fetal marker for risk of small for gestational age at birth. With improvement of ultrasound techniques, more studies have been investigating the alterations of the umbilical cord on pregnancy outcomes.

Objectives: To determine the reference ranges of the umbilical cord area during pregnancy and to find out the association between umbilical cord morphometry and fetal anthropometric measurements.

Patients and Methods: A cross sectional study was carried out on a study population of 278 low-risk pregnant women between 15 and 41 weeks of gestational age. Fetal anthropometric measurements including biparietal diameter, abdominal circumference, and femur length were calculated. The measurements of the cross-sectional area (CSA) and circumference of the umbilical cord, vein and arteries were done on an adjacent plane to the insertion of umbilical cord into the fetus's abdomen. The mean and standard deviation of the CSA of the umbilical cord and the 5th, 10th, 50th, 90th, 95th percentiles of it were calculated for each gestational age. Pearson correlation coefficient was used to assess the correlation between the measures of the cord and fetal anthropometric measurements. Polynomial regression analysis was performed for curves.

Results: The values of the CSA of the umbilical cord, umbilical vein and Wharton's jelly (WJ) increase consistently until 30 weeks of gestation, after which they reach a plateau. There was a significant correlation between anthropometric measurements and umbilical cord measurements especially with the CSA of the umbilical cord, umbilical vein and WJ. The regression equation for the umbilical cord CSA according to gestational age up to 30 weeks was $y=-0.2159 x^{2}+23.828 x-325.59\left(R^{2}=0.6334\right)$ and for the WJ area according to gestational age up to 30 weeks, it was $y=-0.2124 \mathrm{x}^{2}+17.613 \mathrm{x}-221.66\left(\mathrm{R}^{2}=0.4979\right)$.

Conclusion: Reference ranges for umbilical cord CSA have been generated. The CSA of the umbilical cord and other components of it increase as a function of gestational age. These measurements correlate with fetal size.
\end{abstract}

Keywords: Umbilical Cord; Ultrasonography; Fetus

\section{Background}

Umbilical cord is a vital structure of maternal-fetal life that can be used to evaluate pregnancy outcomes. In the past, sonographic investigations of the umbilical cord were limited to identification of the number of vessels and Doppler evaluation of the blood flow $(1,2)$. Umbilical cord morphology has been usually studied by pathologists $(3,4)$. During the past decade, improved ultrasound techniques in measuring the diameter of the umbilical cord and its components resulted in a more advanced perinatal diagnosis (5-7).

Wharton's jelly (WJ) is a network of glycoprotein microfibrils, collagen fibrils and mostly hyaluronic acid that surrounds the umbilical cord and its vessels (8). It supports adequate blood flow to the fetus $(9,10)$. Alterations in umbilical cord and WJ area (11, 12), presence of cysts (13), a single artery, and absence of coiling (14) can be signs of adverse pregnancy outcomes. An association has been described between the amount of WJ and some pathologic conditions such as hypertensive disorders (15) and fetal distress (16). Reduction in WJ and umbilical vein area (6) and alternations in WJ proteins (17) can cause preeclampsia. The absence of WJ has been seen in some cases of prenatal mortality (18). Increased diameter of umbilical cord is reported in gestational diabetes $(7,19)$ and decreased diameter due to umbilical vein reduction and WJ diminution is found in small for gestational age at birth $(5,16,20,21)$.

In order to find any association between the umbilical cord CSA and pregnancy outcome, it is important to know its reference ranges for normal population. The first nomogram of umbilical cord CSA was published in 1994 (22). Thereafter, the reference ranges for umbilical cord CSA and diameter and its association with gestational age and fetal size was introduced for the first time

Copyright (C) 2015, Tehran University of Medical Sciences and Iranian Society of Radiology. This is an open-access article distributed under the terms of the Creative Commons Attribution-NonCommercial 4.0 International License (http://creativecommons.org/licenses/by-nc/4.0/) which permits copy and redistribute the material just in noncommercial usages, provided the original work is properly cited. 
(23). Moreover, a nomogram of WJ and its relation with gestational age and fetal biometric parameters was also established (24). Recently, a reference curve for the crosssectional area of the umbilical cord, its diameter and the diameter of its vessels was introduced (25).

\section{Objectives}

With regard to the potential of the umbilical cord in predicting adverse perinatal situations, the aim of this study was to determine reference ranges of the umbilical cord CSA and to find out if umbilical cord CSA and its component parameters have any association with fetal biometric measurements and gestational age.

\section{Patients and Methods}

A cross-sectional study was carried out at Mahdieh hospital of Shahid Beheshti university of medical sciences, Iran, on a study population of 278 low risk pregnant women between 15 and 41 weeks of gestational age who had been referred to the ultrasound unit for a routine sonographic scan between 2011 and 2012.

Inclusion criteria were: a single pregnancy with a gestational age based on the last menstrual date (LMP) or established by ultrasonography performed until the 15th week; intact membrane; living fetus; normal Doppler flowmetry of the umbilical artery, and amniotic fluid in$\operatorname{dex}(\mathrm{AFI})$ (26) between the 10th and 90th percentiles.

Patients with maternal disease and pregnancy complication such as diabetes, hypertensive disorder, and fetal weight estimation below the 10th percentile and above the 90th percentile for the correspondent gestational age were excluded. Hadlock's formula (27) was used to estimate fetal weight.

Each patient was included only once. In addition to other parameters routinely evaluated during pregnancy such as placental location, fetus present and fetus sex, biparietal diameter (BPD), head circumference (HC), abdominal circumference (AC), and femur length (FL) were measured for estimating fetal weight. The measurements of the CSA and circumference of the umbilical cord, vein and arteries were done on an adjacent plane to the insertion of umbilical cord into fetal abdomen, placing the markers at its outer borders, with maximum magnification of the image. These values were computed using the software of the ultrasound machine. The CSA and circumference of two arteries were measured. The bigger artery was named 2 and the smaller one was named 1 . The WJ area was calculated by subtracting the total vessel area from the umbilical cord area. Three to five measures were performed on each cord, and the average of these measures was used as reference standard. All examinations were performed with Accuvix XQ MYLAB70 device.

Statistical analysis was performed using SPSS for windows, version 16.0 (SPSS Inc. Chicago, IL, USA). First the mean and standard deviation of the CSA of the umbilical cord were calculated in accordance with age and parity. The differences were evaluated using Wilcoxon, MannWhitney and Kruskal-Wallis tests for non-parametric data. Mean and standard deviation of the area of the umbilical cord and 5th, 10th, 50th, 90th, and 95th percentiles of it were calculated for each gestational age. Patients were divided into two groups according to gestational age of 30 weeks. The mean and standard deviation of the CSA and circumference of the umbilical cord, vein and arteries were calculated in each group. Pearson correlation coefficient was used to assess the correlation between the measures of the cord and the fetal anthropometric measurements. Results were significant at $\mathrm{P}<$ 0.05. Polynomial regression analysis was performed for curves and $\mathrm{R}^{2}$ is presented.

\section{Results}

A total number of 278 pregnant women were evaluated. The mean age was $27 \pm 5.5$ years (range: 15 to 40 years). The mean gestational age was $33.7 \pm 5.8$ weeks. Nulliparous pregnancies included $55 \%$ of the patients and $43 \%$ of the fetuses were male. Some general characteristics of our study are shown in Table 1 . There was no association between the area of umbilical cord, and age and parity. Table 2 shows that the mean of all the umbilical cord parameters are significantly lower in gestational week $\leq 30$, so these mean values increased significantly during pregnancy. Table 3 shows descriptive measurements and 5th, 10th, 50th, 90th, and 95th percentiles of the cross-sectional area of the umbilical cord for each gestational age.

The values of the area of the umbilical cord, umbilical vein and WJ increase consistently until 30 weeks of gestation, after which they reach a plateau (Figures 1, 3 and 5). Figures 2, 4 and 6 show these values in gestational age $\leq 30$.

There was a statistically significant correlation between anthropometric measurements and the crosssectional area of the umbilical cord in $\leq 30$ weeks of gestation (CSA and BPD $\mathrm{r}=0.77, \mathrm{P}<0.001$; CSA and AC $\mathrm{r}=0.8, \mathrm{P}<0.001$; CSA and FL $\mathrm{r}=0.75, \mathrm{P}<0.001$; CSA and $\mathrm{HC} \mathrm{r}=0.6, \mathrm{P}<0.001$ ), umbilical vein CSA (CSA and BDP $\mathrm{r}$ $=0.57, \mathrm{P}<0.001 ;$ CSA and $\mathrm{AC} \mathrm{r}=0.57, \mathrm{P}<0.001$; area and FL $r=0.57, \mathrm{P}<0.001$; area and $\mathrm{HC} r=0.37, \mathrm{P}<0.03$ ) and WJ CSA (CSA and BPD $r=0.61, \mathrm{P}<0.001$; CSA and AC $\mathrm{r}=$ $0.72, \mathrm{P}<0.001$; CSA and FL $\mathrm{r}=0.68, \mathrm{P}<0.001$; CSA and HC $\mathrm{r}=0.58, \mathrm{P}<0.001$ ). Mild significant correlation was found between anthropometric measurements and umbilical vein circumference $(r=0.3)$ and umbilical artery circumference $(r=0.3)$. No strong correlation was found between anthropometric measurements and umbilical cord circumference, umbilical arteries CSA. There was a significant correlation between gestational age and umbilical cord CSA $(\mathrm{r}=0.8, \mathrm{P}<0.001)$, WJ area $(\mathrm{r}=0.73, \mathrm{P}<$ $0.001)$, umbilical vein CSA $(\mathrm{r}=0.57, \mathrm{P}<0.001)$, umbilical vein circumference $(\mathrm{r}=0.34, \mathrm{P}<0.01)$ and umbilical artery circumference $(r=0.36, P<0.01)$. 
Rostamzadeh S et al.

Table 1. Mean Cross-Sectional Area of the Umbilical Cord According to Age and Parity

\begin{tabular}{|c|c|c|c|}
\hline & No.(\%) & Mean \pm SD & P Value \\
\hline Maternal Age & & & $0.151^{\mathrm{a}}$ \\
\hline$\leq 29$ & $175(67.0)$ & $174.7 \pm 54.4$ & \\
\hline$\geq 30$ & $86(33.0)$ & $180.7 \pm 58.8$ & \\
\hline Parity & & & $0.079^{a}$ \\
\hline Nullipara & $123(49.4)$ & $168.1 \pm 50.2$ & \\
\hline$\geq 1$ & $126(50.6)$ & $182.6 \pm 58.6$ & \\
\hline Parity & & & $0.156^{b}$ \\
\hline 0 & $123(49.4)$ & $168.1 \pm 50.2$ & \\
\hline 1 & $86(34.5)$ & $182.0 \pm 53.2$ & \\
\hline 2 & $27(10.8)$ & $182.4 \pm 71.1$ & \\
\hline 3 & $10(4.0)$ & $192.5 \pm 71.8$ & \\
\hline 4 & $2(0.8)$ & $130.5 \pm 23.3$ & \\
\hline 5 & $0(0.0)$ & - & \\
\hline 6 & $1(0.4)$ & 246.0 & \\
\hline
\end{tabular}

a Mann-Whitney test.

b Kruskal-Wallis test.

Table 2. Mean of the Area and Circumference of the Umbilical Cord, Umbilical Vein and Arteries in Different Age Groups

\begin{tabular}{|c|c|c|c|}
\hline & Mean \pm SD & No.(\%) & PValue \\
\hline Umbilical Cord Cross Sectional Area & & & $<0.001$ \\
\hline$\leq 30$ & $49(19.1)$ & $133.2 \pm 56.2$ & \\
\hline$>30$ & $208(80.9)$ & $186.4 \pm 51.2$ & \\
\hline Umbilical Cord Circumference & & & $<0.001$ \\
\hline$\leq 30$ & 49 (19.1) & $48.0 \pm 56.2$ & \\
\hline$>30$ & $208(80.9)$ & $49.2 \pm 9.0$ & \\
\hline Umbilical Vein Cross Sectional Area & & & $<0.001$ \\
\hline$\leq 30$ & $48(18.8)$ & $33.5 \pm 16.7$ & \\
\hline$>30$ & $207(81.2)$ & $52.1 \pm 15.6$ & \\
\hline Umbilical Vein Circumference & & & $<0.001$ \\
\hline$\leq 30$ & $48(18.8)$ & $22.0 \pm 10.3$ & \\
\hline$>30$ & $207(81.2)$ & $26.4 \pm 9.7$ & \\
\hline First Umbilical Artery Cross Sectional Area & & & $<0.001$ \\
\hline$\leq 30$ & $45(18.2)$ & $12.8 \pm 13.0$ & \\
\hline$>30$ & $202(81.8)$ & $15.5 \pm 7.7$ & \\
\hline First Umbilical Artery Circumference & & & $<0.001$ \\
\hline$\leq 30$ & $45(18.3)$ & $11.7 \pm 4.8$ & \\
\hline$>30$ & $201(81.7)$ & $14.4 \pm 7.3$ & \\
\hline Second Umbilical Artery Cross Sectional Area & & & $<0.001$ \\
\hline$\leq 30$ & $45(18.3)$ & $11.8 \pm 12.9$ & \\
\hline$>30$ & $201(81.7)$ & $15.2 \pm 8.6$ & \\
\hline Second Umbilical Artery Circumference & & & $<0.001$ \\
\hline$\leq 30$ & $45(18.3)$ & $11.6 \pm 5.1$ & \\
\hline$>30$ & $201(81.7)$ & $14.0 \pm 7.5$ & \\
\hline Wharton Jelly Area & & & $<0.001$ \\
\hline$\leq 30$ & $57(21.0)$ & $64.3 \pm 47.7$ & \\
\hline$>30$ & $215(79.0)$ & $91.7 \pm 46.4$ & \\
\hline
\end{tabular}


Rostamzadeh S et al.

Table 3. Descriptive Measurements and Percentiles 5th, 10th, 50th, 90th, and 95th of the Cross-Sectional Area of Umbilical Cord for Each Gestational Age

\begin{tabular}{|c|c|c|c|c|c|c|c|}
\hline \multirow{2}{*}{$\begin{array}{l}\text { Gestational Age } \\
\text { (week) }\end{array}$} & \multirow[t]{2}{*}{ No.(\%) } & \multirow[t]{2}{*}{ Mean \pm SD } & \multicolumn{5}{|c|}{ Percentiles } \\
\hline & & & 5 & 10 & 50 & 90 & 95 \\
\hline 15 & $2(0.7)$ & & & & & & \\
\hline 16 & $1(0.4)$ & & & & & & \\
\hline 17 & $1(0.4)$ & & & & & & \\
\hline 18 & $2(0.7)$ & & & & & & \\
\hline 20 & $3(1.1)$ & $47.2 \pm 33.1$ & 9.0 & 9.0 & 65.5 & & \\
\hline 21 & $7(2.6)$ & $92.1 \pm 23.8$ & 67.0 & 67.0 & 84.0 & & \\
\hline 22 & $7(2.6)$ & $89.5 \pm 33.4$ & 28.0 & 28.0 & 96.0 & & \\
\hline 23 & $1(0.4)$ & & & & & & \\
\hline 24 & $4(1.5)$ & $99.3 \pm 14.2$ & 82.5 & 82.5 & 99.3 & & \\
\hline 25 & $7(2.6)$ & $145.4 \pm 45.5$ & 89.0 & 89.0 & 148.0 & & \\
\hline 26 & $5(1.8)$ & $166.4 \pm 39.0$ & 122.0 & 122.0 & 149.0 & & \\
\hline 27 & $1(0.4)$ & & & & & & \\
\hline 28 & $3(1.1)$ & $209.9 \pm 22.5$ & 194.0 & 194.0 & 209.9 & & \\
\hline 29 & $7(2.6)$ & $178.9 \pm 32.9$ & 138.5 & 138.5 & 173.0 & & \\
\hline 30 & $6(2.2)$ & $187.8 \pm 20.0$ & 161.0 & 161.0 & 186.3 & & \\
\hline 31 & $9(3.3)$ & $182.4 \pm 57.8$ & 102.0 & 102.0 & 183.0 & & \\
\hline 32 & $17(6.2)$ & $185.2 \pm 45.5$ & 126.0 & 130.8 & 180.5 & 251.8 & \\
\hline 33 & $15(5.5)$ & $181.1 \pm 41.9$ & 139.0 & 139.8 & 160.0 & 258.4 & \\
\hline 34 & $22(8.1)$ & $195.8 \pm 55.0$ & 42.7 & 133.6 & 202.2 & 270.2 & 292.7 \\
\hline 35 & $19(7.0)$ & $187.3 \pm 46.7$ & 124.0 & 126.1 & 180.6 & 274.2 & \\
\hline 36 & $20(7.3)$ & $190.0 \pm 36.2$ & 124.5 & 139.4 & 189.5 & 245.9 & \\
\hline 37 & $30(11.0)$ & $167.4 \pm 41.9$ & 99.6 & 114.3 & 171.3 & 236.8 & 243.6 \\
\hline 38 & $28(10.3)$ & $186.5 \pm 37.3$ & 118.2 & 141.6 & 179.7 & 243.6 & 253.5 \\
\hline 39 & $30(11.0)$ & $198.6 \pm 77.7$ & 91.5 & 120.7 & 194.9 & 286.6 & 420.6 \\
\hline 40 & $24(8.8)$ & $188.2 \pm 50.4$ & 122.3 & 125.3 & 183.8 & 279.0 & 295.0 \\
\hline 41 & $2(0.7)$ & $182.3 \pm 78.7$ & 126.7 & 126.7 & 182.3 & & \\
\hline
\end{tabular}

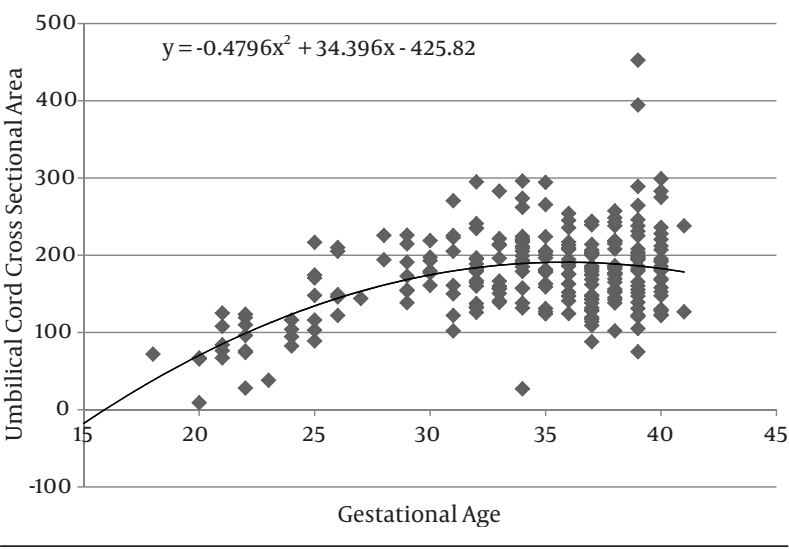

Figure 1. The area of the umbilical cord according to gestational age during pregnancy

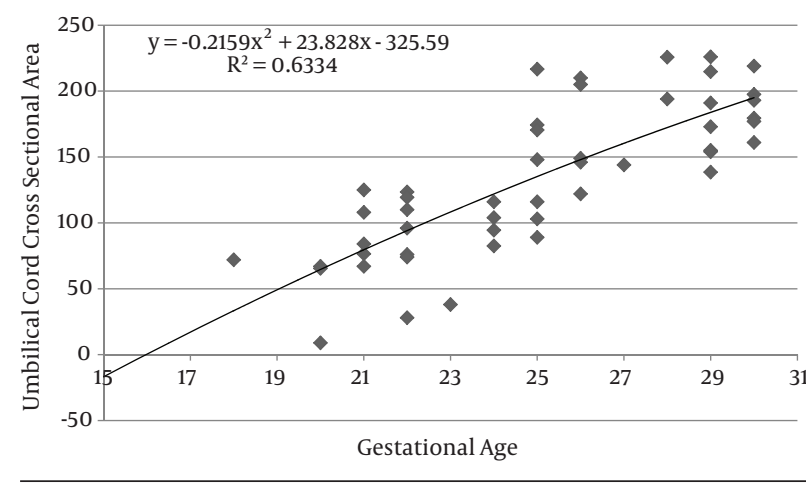

Figure 2. The area of the umbilical cord according to gestational age up to 30 weeks 


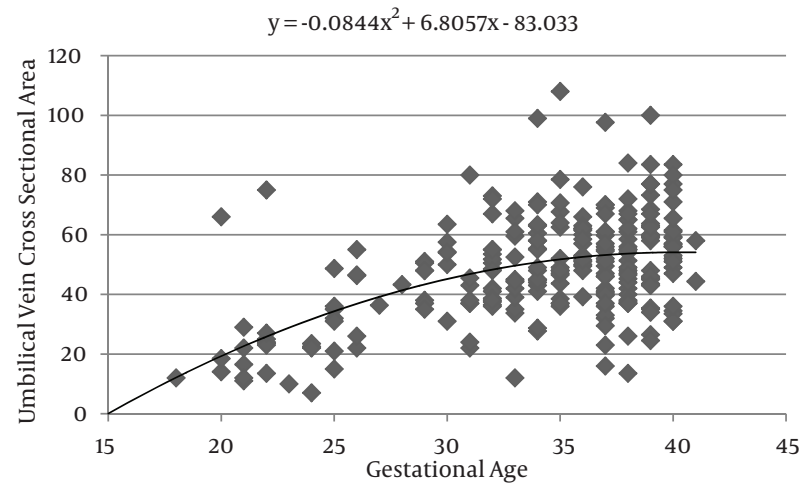

Figure 3. The area of the umbilical vein according to gestational age during pregnancy

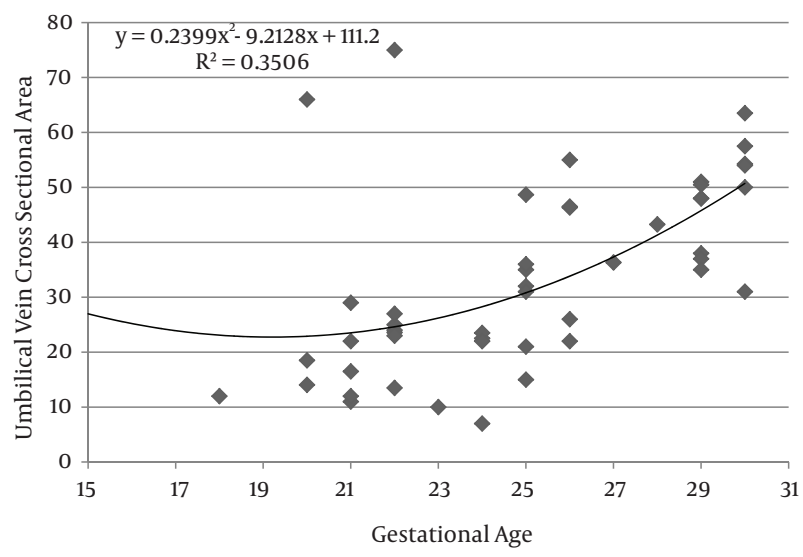

Figure 4. The area of the umbilical vein according to gestational age up to 30 weeks

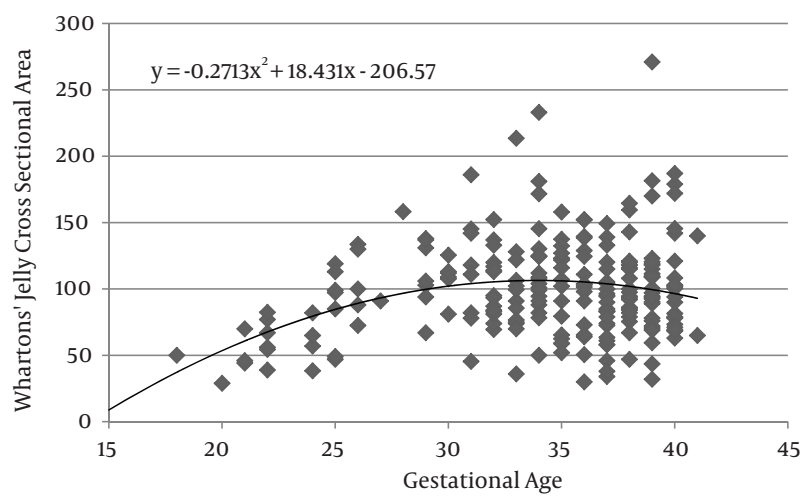

Figure 5. The area of Whartons' jelly according to gestational age during pregnancy

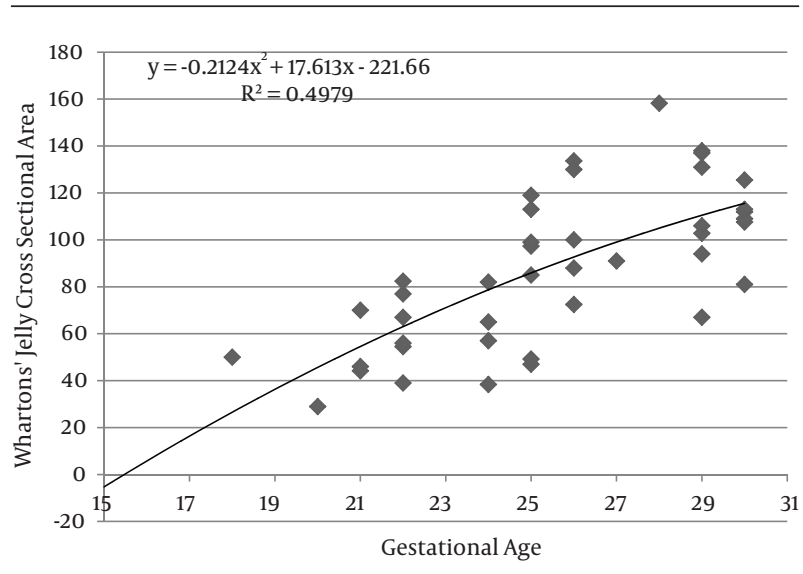

Figure 6. The area of Whartons' jelly according to gestational age up to 30 weeks

\section{Discussion}

In this study we found a significant increase in the CSA and circumference of the umbilical cord, umbilical vein and umbilical arteries during pregnancy. There is a significant consistent increase in the CSA of the umbilical cord, the area of umbilical vein and the CSA of WJ during pregnancy up to 30 weeks. Afterward, these measures remained stable and reached a plateau. During pregnancy, there was a strong correlation between anthropometric measurements and the CSA of the umbilical cord, the CSA of umbilical vein and the CSA of WJ up to 30 weeks.

It has been established that presence of lean umbilical cord with reduced Wharton's jelly in sonographic scans is a marker for delivery of a fetus at risk of being small for gestational age at birth $(5,16,20,21)$. By improving ultrasound techniques, more studies have been investigating the alterations of the umbilical cord on pregnancy outcomes. Some studies described correlations between the amount of WJ and hypertensive disorder (15), fetal distress (16), preeclampsia $(6,17)$, and gestational diabetes $(7,19)$.

Evaluating umbilical cord parameters and comparing them with normal values help us in the early identification of fetal abnormalities. The first study in this field was in 1994 and it showed that the diameter of the umbilical cord and its vessels increase progressively with gestational age until 32 weeks followed by a plateau (22). The second study published reference ranges for umbilical cord diameter and CSA and showed that these values increase with gestational age until 32 weeks and correlate with fetal size (23). Moreover, a nomogram of WJ was also established and it showed that WJ area increases up to 32 weeks and that it correlated with fetal size up to 32 weeks (24). Togni et al. found the same result, but the values increased up to 33 weeks (28). Recently, a reference curve for the cross-sectional area of the umbilical cord, its diameter and the diameter of its vessels was introduced that had the same results as other studies (25). In our study, 
there was a significant increase in the CSA and circumference of the umbilical cord, umbilical vein and umbilical arteries and WJ area during pregnancy as a function of gestational age. There was a significant consistent increase in the CSA of the umbilical cord, umbilical vein and WJ up to 30 weeks of gestation followed by a plateau. This is consistent with other studies although it reached a plateau earlier (22-25, 28).

WJ is a network of collagen fibrils that has many interconnected cavities. The system of cavities of WJ have a role in storing water and substances of jelly so it can facilitate exchanging trophic metabolites either from or to the umbilical vessels and amniotic fluid (29). Increase in WJ quantities during normal pregnancy is mostly responsible for changes in macroscopic appearance of the umbilical cord in the second and third trimesters (30). Therefore, we expect umbilical cord area and WJ area follow the same pattern during pregnancy.

The ratio of the $\mathrm{WJ}$ area to the total umbilical cord area decreases significantly with advancing gestation (24). Also pathological studies have shown that the water content of the umbilical cord is significantly lower in term than in preterm neonates with a progressive reduction from 30 weeks gestation to term (31), so as it has been shown in our study after 30 weeks, water content of the umbilical cord reduced and our nomogram reached a plateau.

The correlation between WJ area and anthropometric measurements up to 30 weeks can be explained by the role of WJ during pregnancy. Pathologists have showed that the cells of WJ can act like smooth muscle cells and participate in the regulation of umbilical blood flow (32). In addition, it has been shown that infants born to women with higher pregnancy weight have more quantities of WJ around their umbilical cord vessels (33).

Our study is limited since our sample size was smaller in comparison to other studies. Besides, because we only performed sonographic scans on pregnant women who came for a routine sonographic scan in one hospital and most of these routine sonogaphic scans are usually not done in the early weeks of pregnancy, our data in those weeks is limited. However, the results of our study support previous observations and it could be due to the strong correlation that exists.

Measuring umbilical cord parameters in routine prenatal ultrasound scan inthe second trimester of pregnancy is an easy measurement technique. It can help us in the early detection of abnormalities in pregnancies such as diabetes mellitus. Therefore, measurement of umbilical cord parameters is highly recommended in the routine prenatal ultrasonography.

\section{Authors' Contributions}

Study concept and design: Sheida Rostamzadeh and Mona Shahriari. Analysis and interpretation of data: Madjid Shakiba, Sheida Rostamzadeh, and Mona Shahriari. Drafting of the manuscript: Mona Shahriari and
Sheida Rostamzadeh. Critical revision of the manuscript for important intellectual content: Sheida Rostamzadeh, Mona Shahriari and Mojgan Kalantari. Statistical analysis: Madjid Shakiba. Developing the original idea: Mojgan Kalantari.

\section{References}

1. Wu MH, Chang FM, Shen MR, Yao BL, Chang $\mathrm{CH}$, Yu CH, et al. Prenatal sonographic diagnosis of single umbilical artery. J Clin $\mathrm{Ul}$ trasound. 1997;25(8):425-30.

2. Scorza WE, Nardi D, Vintzileos AM, Fleming AD, Rodis JF, Campbell WA. The relationship between umbilical artery Doppler velocimetry and fetal biometry. Am J Obstet Gynecol. 1991;165(4 Pt 1):1013-9.

3. Malpas P, Symonds EM. Observations on the structure of the human umbilical cord. Surg Gynecol Obstet. 1966;123(4):746-50.

4. Heifetz SA. Single umbilical artery. A statistical analysis of 237 autopsy cases and review of the literature. Perspect Pediatr Pathol. 1984;8(4):345-78.

5. Raio L, Ghezzi F, Di Naro E, Franchi M, Maymon E, Mueller MD, et al. Prenatal diagnosis of a lean umbilical cord: a simple marker for the fetus at risk of being small for gestational age at birth. Ultrasound Obstet Gynecol.1999;13(3):176-80.

6. Raio L, Ghezzi F, Di Naro E, Franchi M, Bolla D, Schneider H. Altered sonographic umbilical cord morphometry in early-onset preeclampsia. Obstet Gynecol. 2002;100(2):311-6.

7. Weissman A, Jakobi P. Sonographic measurements of the umbilical cord in pregnancies complicated by gestational diabetes. $J$ Ultrasound Med.1997;16(10):691-4

8. Wang HS, Hung SC, Peng ST, Huang CC, Wei HM, Guo YJ, et al. Mesenchymal stem cells in the Wharton's jelly of the human umbilical cord. Stem Cells. 2004;22(7):1330-7.

9. Nanaev AK, Kohnen G, Milovanov AP, Domogatsky SP, Kaufmann P. Stromal differentiation and architecture of the human umbilical cord. Placenta. 1997;18(1):53-64.

10. Ferguson VL, Dodson RB. Bioengineering aspects of the umbilical cord. Eur J Obstet Gynecol Reprod Biol. 2009;144 Suppl 1:S108-13.

11. Hasegawa J, Matsuoka R, Ichizuka K, Sekizawa A, Okai T. Ultrasound diagnosis and management of umbilical cord abnormalities. Taiwan J Obstet Gynecol. 2009;48(1):23-7.

12. Di Naro E, Ghezzi F, Raio L, Franchi M, D'Addario V. Umbilical cord morphology and pregnancy outcome. Eur J Obstet Gynecol Reprod Biol. 2001;96(2):150-7.

13. Ross JA, Jurkovic D, Zosmer N, Jauniaux E, Hacket E, Nicolaides $\mathrm{KH}$. Umbilical cord cysts in early pregnancy. Obstet Gynecol. 1997;89(3):442-5.

14. Strong TJ, Elliott JP, Radin TG. Non-coiled umbilical blood vessels: a new marker for the fetus at risk. Obstet Gynecol. 1993;81(3):409-11.

15. Bankowski E, Sobolewski K, Romanowicz L, Chyczewski L, Jaworski S. Collagen and glycosaminoglycans of Wharton's jelly and their alterations in EPH-gestosis. Eur J Obstet Gynecol Reprod Biol. 1996;66(2):109-17.

16. Goodlin RC. Fetal dysmaturity, "lean cord," and fetal distress. Am JObstet Gynecol. 1987;156(5):1357.

17. Bankowski E, Palka J, Jaworski S. Preeclampsia is associated with alterations in insulin-like growth factor (IGF)-1 and IGF-binding proteins in Wharton's jelly of the umbilical cord. Clin Chem Lab Med. 2000;38(7):603-8.

18. Labarrere C, Sebastiani M, Siminovich M, Torassa E, Althabe O Absence of Wharton's jelly around the umbilical arteries: an unusual cause of perinatal mortality. Placenta. 1985;6(6):555-9.

19. Singh SD. Gestational diabetes and its effect on the umbilical cord. Early Hum Dev. 1986;14(2):89-98.

20. Ghezzi F, Raio L, Gunter Duwe D, Cromi A, Karousou E, Durig P. Sonographic umbilical vessel morphometry and perinatal outcome of fetuses with a lean umbilical cord. J Clin Ultrasound. 2005;33(1):18-23.

21. Qureshi F, Jacques SM. Marked segmental thinning of the umbilical cord vessels. Arch Pathol Lab Med. 1994;118(8):826-30.

22. Weissman A, Jakobi P, Bronshtein M, Goldstein I. Sonographic 


\section{Rostamzadeh S et al.}

measurements of the umbilical cord and vessels during normal pregnancies. JUltrasound Med. 1994;13(1):11-4

23. Raio L, Ghezzi F, Di Naro E, Gomez R, Franchi M, Mazor M, et al. Sonographic measurement of the umbilical cord and fetal anthropometric parameters. Eur J Obstet Gynecol Reprod Biol. 1999;83(2):131-5.

24. Ghezzi F, Raio L, Di Naro E, Franchi M, Balestreri D, D'Addario V. Nomogram of Wharton's jelly as depicted in the sonographic cross section of the umbilical cord. Ultrasound Obstet Gynecol. 2001;18(2):121-5.

25. Barbieri C, Cecatti JG, Surita FG, Marussi EF, Costa JV. Sonographic measurement of the umbilical cord area and the diameters of its vessels during pregnancy. J Obstet Gynaecol. 2012;32(3):230-6.

26. Phelan JP, Smith CV, Broussard P, Small M. Amniotic fluid volume assessment with the four-quadrant technique at 36-42 weeks' gestation.J Reprod Med.1987;32(7):540-2.

27. Hadlock FP, Harrist RB, Martinez-Poyer J. In utero analysis of fetal growth: a sonographic weight standard. Radiology.
1991;181(1):129-33.

28. Togni FA, Araujo Junior E, Moron AF, Vasques FA, Torloni MR, Nardozza LM, et al. Reference intervals for the cross sectional area of the umbilical cord during gestation. J Perinat Med. 2007;35(2):130-4

29. Vizza E, Correr S, Goranova V, Heyn R, Angelucci PA, Forleo R, et al. The collagen skeleton of the human umbilical cord at term. A scanning electron microscopy study after $2 \mathrm{~N}-\mathrm{NaOH}$ maceration. Reprod Fertil Dev. 1996;8(5):885-94.

30. Scott JM, Wilkinson R. Further studies on the umbilical cord and its water content. J Clin Pathol.1978;31(10):944-8.

31. Sloper KS, Brown RS, Baum JD. The water content of the human umbilical cord. Early Hum Dev. 1979;3(2):205-10.

32. Gebrane-Younes J, Hoang NM, Orcel L. Ultrastructure of human umbilical vessels: a possible role in amniotic fluid formation? Placenta.1986;7(2):173-85.

33. Gill P, Jarjoura D. Wharton's jelly in the umbilical cord. A study of its quantitative variations and clinical correlates. J Reprod Med. 1993;38(8):611-4. 